\title{
A Composite Cooling Powder and Its Thixotropic Hydrogel
}

\author{
Mingxi Chen \\ School of Engineering, Southern University of Science and Technology, Shenzhen, China \\ Email: 11713001@mail.sustech.edu.cn
}

How to cite this paper: Chen, M.X (2021) A Composite Cooling Powder and Its Thixotropic Hydrogel. Advances in Chemical Engineering and Science, 11, 29-37. https://doi.org/10.4236/aces.2021.111003

Received: October 18, 2020

Accepted: January 8, 2021

Published: January 11, 2021

Copyright (c) 2021 by author(s) and Scientific Research Publishing Inc. This work is licensed under the Creative Commons Attribution International License (CC BY 4.0).

http://creativecommons.org/licenses/by/4.0/ (c) (i) Open Access

\begin{abstract}
Due to large volume and high hardness of thermal insulation materials mostly used in high temperature fields, a composite cooling powder and its thixotropic hydrogel for thermal protection are presented. The core of composite cooling material powder is super absorbent polymer, composing with metal salt, polysaccharide hydrosol and inorganic particles and other modifiers through a series of composite process, which can be easily stored for a long time. When needed, the powder can be mixed with water to obtain a kind of thixotropic hydrogel in a very short time. Experimental results show this thermal protection technology with thixotropic ability has excellent thermal protection performance, meanwhile flexible, adhesive and low cost, which exerts instantaneous cooling, efficient thermal protection and long-lasting flame-retardant protection.
\end{abstract}

\section{Keywords}

Composite Powder, Hydrogel, Super Absorbent Polymer, Thixotropic, Cooling, Thermal Protection

\section{Introduction}

Super Absorbent Polymer (SAP) is a new type of functional polymer material. It has excellent hydrophilic properties, high swelling ratio and biological capacitive [1]. Nowadays it's widely used in industry [2], agriculture [3], food [4], medical and health [5] and other fields.

SAP has a large number of hydrophilic groups such as carboxyl and hydroxyl groups. Because of osmotic pressure and static electricity, it can absorb water hundreds or even thousands of times its own weight, which is far superior to common absorbent materials such as cotton, sponge, etc. After absorbing water, a gel-like product is formed, which is called hydrogel. Hydrogel's unique 
three dimensional spatial network structure can firmly bind water [6]. On the one hand, water molecules are not easily squeezed out due to mechanical pressure. Therefore, hydrogel has good water retention performance even under high temperature conditions. While water has a rather high heat capacity, hydrogels also have considerable heat capacity and exhibit excellent thermal protection and cooling ability.

After SAP absorbs certain amount of water, hydrogels formed have good strength, at the same time thermal protection performance improves as water radio rises [7]. However, when excessive water is absorbed, the strength and adhesive property of hydrogels are greatly reduced, and hydrogels are amorphous. Therefore, the water-to-powder ratio must be controlled properly.

Besides, due to simple hydrogel's amorphous form, low adhesion to three dimensional objects, and poor high-temperature structural stability, something must be done to make it easy to use for thermal insulation protection.

In this paper, we proposed a technical solution: A kind of composite heat insulating powder is prepared by a composite process, which contains super absorbent polymer with water-soluble metal salts, water-soluble polysaccharide hydrosol, water-insoluble inorganic particles and other modifiers. The power can be used easily by absorbing water, and the hydrogel formed shows excellent thermal protection property.

\section{Experiment}

\subsection{Materials (Table 1)}

Table 1. Main components and mass fractions of composite.

\begin{tabular}{cccccccc}
\hline & $\begin{array}{c}\text { Super } \\
\text { absorbent } \\
\text { polymer }\end{array}$ & Metal salt & $\begin{array}{c}\text { Coagulated } \\
\text { polysaccharide }\end{array}$ & $\begin{array}{c}\text { Heat- } \\
\text { insulation } \\
\text { particles }\end{array}$ & $\begin{array}{c}\text { Flame } \\
\text { retardant } \\
\text { particles }\end{array}$ & $\begin{array}{c}\text { Nano } \\
\text { oxide }\end{array}$ & Modifier \\
Sample 1 & 65 & 6 & 10 & 3.5 & 10 & 5 & 0.5 \\
Sample 2 & 85 & 3 & 2 & 2 & 4 & 2.5 & 1.5 \\
Sample 3 & 74 & 3 & 12 & 6 & 2 & 2.5 & 0.5 \\
Sample 4 & 82 & 4 & 4 & 4.5 & 2 & 1.5 & 2 \\
Sample 5 & 66 & 5 & 10 & 10 & 3 & 4.5 & 1.5 \\
Comparison 1 & 71 & 0 & 10 & 4 & 10 & 5 & 0 \\
Comparison 2 & 76 & 5 & 0 & 10 & 3 & 4.5 & 1.5 \\
Comparison 3 & 90 & 5 & 5 & 0 & 0 & 0 & 0 \\
\hline
\end{tabular}

Note: The figures in the table represent the mass content.

\subsection{Preparation Process}

According to Table 1, all raw materials according to the proportion are mixed at $500-800 \mathrm{rpm}$ for $2-5$ minutes in the high-speed mixing machine. Then the machine speed turn to 3000 - $3800 \mathrm{rpm}$ for 15 - 20 minutes. During this period, the mixtures temperature is controlled not high than $60^{\circ} \mathrm{C}$. After that, the mix- 
ture is cooled to room temperature naturally. The mixture is the composite cooling powder.

Mixed with water (pure water, tap water, natural water or desalination water) at 1/150-200 mass radio, the powder can absorb water quickly and form hydrogel within $1 \mathrm{~min}$.

\subsection{Test}

All samples were mixed with tap water in the mass ratio of 1:150, tested after forming hydrogel within 1 minute.

\subsubsection{Thermal Protection Performance Test}

Thermal protection performance test (TPP) is a special test generally used to test the thermal protection ability of fabrics and other materials against the combined action of heat radiation and heat convection. This method relates thermal protection of materials with human body feeling, and can evaluate practical application effect of thermal protection objectively. Now it has been listed as a general test method. We use it as the main means to test thermal protection performance of hydrogel.

The specific test method is to place the sample horizontally on a specific two heat sources, including heat convection and heat radiation. A copper sheet heat flow meter placed on the other side of the sample measures the temperature on the back of the sample. Compared with Stoll standard curve, the time required for second-degree body burning $t 2$ is obtained, and the TPP value is obtained by multiplying the exposure heat flow $q$, which is calculated as TPP $=t 2 \times q$. The greater the TPP value, the better the thermal protection performance of materials.

All hydrogel thickness is $1 \mathrm{~mm}$ for TPP test, which is the minimum thickness during application.

\subsubsection{Thixotropy}

Thixotropy of hydrogel is characterized by consistency degree. Here it's defined as the ratio of the outflow time of hydrogel after 30 minutes of standing in the viscometer to that of 30 seconds, and the average value of three tests is taken.

\subsubsection{Adhesive Property}

Hydrogel is amorphous, and it cannot be characterized according to the standard of cured adhesive. Here we designed a simple test method, shown in Figure 1.

Spray hydrogel to a vertical board at $0.15 \mathrm{MPa}$ for $10 \mathrm{~s}$. The board was made from common plywood purchased from market. After $1 \mathrm{~min}$, the thickness of hydrogel attached to the board can be used to characterize hydrogel's adhesive property, and average value of three different positions was taken.

\subsubsection{Residual Ratio}

Thermogravimetric Analysis test was used to analysis composite powder's residual 


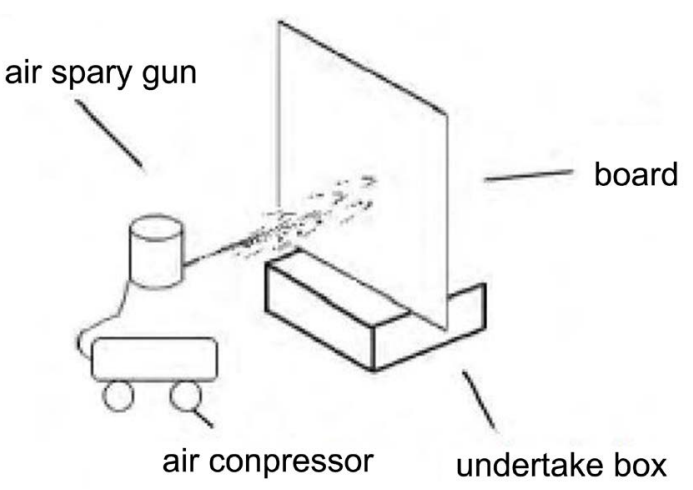

Figure 1. Schematic diagram of hydrogel adhesion test method.

percentage. The test was in air atmosphere at $10^{\circ} \mathrm{C} / \mathrm{min}$ heating rate. Residual ratio at $600^{\circ} \mathrm{C}$ was assigned.

\section{Results and Analysis}

\subsection{Analysis of Formula Composition}

There are three ways of heat transfer: heat conduction, heat convection and heat radiation. Materials with good thermal protection property should block heat from these three aspects at the same time. Hydrogel is a core-shell structure system containing two phases of polymer and liquid. If doped specialized by insoluble particles, composite hydrogel will get excellent thermal insulation properties for blocking these three aspects simultaneously.

As showed in Table 1, multiple ingredients are added to SAP. 8 recipes are designed for optimized composite formulation including 5 sets of test formulas and 3 sets of comparison formulas.

The general design idea is as follows: The unique three-dimensional spatial network structure of SAP can bind water firmly, and the hydrogel formed has excellent water retention performance even under high temperature. Water has considerable heat capacity and evaporation heat, showing excellent cooling ability [8]. Theoretically hydrogel also has excellent cooling and heat absorption performance. Water-soluble metal salts can accelerate the formation speed of the hydrogel, avoiding the white core phenomenon [9] effectively. At the same time, metal salts belong to flame retardants which can significantly improve fire resistance of the hydrogel. Water-soluble polysaccharides can enhance three dimensional adhesion of hydrogel, and their thermal expansion and thermal curing character can further ensure the high-temperature adhesion and stability of hydrogel [10] [11]. Then insolubly particles such as heat-insulating particles, flame-retardant particles and nano-particles can empower hydrogel a more stable three-dimensional skeleton structure, heat-insulating, flame retardant and heat reflection properties are enhanced respectively [12]. Particle size design is designed especially for hydrogel's thixotropic property [13]. At last, modifier plays the role of optimizing and perfecting the whole formulation design.

The test results of each sample and comparison are shown in Table 2. 
Table 2. Performance comparison of composite flame-retardant thermal insulation powder and its hydrogel.

\begin{tabular}{ccccc}
\hline & $\begin{array}{c}\text { Thermal protection } \\
\text { performance }\end{array}$ & Thixotropy & $\begin{array}{c}\text { Adhesion } \\
/ \mathrm{mm}\end{array}$ & $\begin{array}{c}\text { Carbon yield } \\
\%\end{array}$ \\
\hline Sample 1 & 2206 & 2.53 & 7.8 & 40 \\
Sample 2 & $>2490$ & 1.87 & 5.3 & 33 \\
Sample 3 & $>2490$ & 2.21 & 8.2 & 35 \\
Sample 4 & 1801 & 1.97 & 6.5 & 33 \\
Sample 5 & 2490 & 2.42 & 7.7 & 42 \\
Comparison 1 & $/$ & $/$ & $/$ & 43 \\
Comparison 2 & 2016 & 2.24 & 3.2 & 39 \\
Comparison 3 & 1460 & 1.46 & 6.1 & 25 \\
\hline
\end{tabular}

Note: / means untested.

It is clear that composite hydrogels obtained according to the mechanism analysis above, that is samples 1 to 5 , all have good thermal protection performance, suitable thixotropy, strong adhesion and good high-temperature structural stability.

Comparison 1, without metal salt and modifier, formed poor dissolved hydrogel. Even after 1 hour later, there were still some powders undissolved, which was called "white core" phenomenon. Therefore, we only carried out the carbon residual rate test for it. Comparison 2, without polysaccharide, formed poor adhesive hydrogel, which is significantly lower than that of the other samples. Comparison 3, without insoluble particles, flame retardant or nano-oxide, formed poor thixotropic hydrogel with considerably lower residue ratio.

It can be easily got the conclusion that the formula design is scientific and the composition proportion is reasonable. The resulting composite dry powders are easy to form hydrogels, and the formed hydrogel has excellent thermal protection performance, suitable thixotropy and adhesion properties.

\subsection{Analysis of Thermal Protection Mechanism}

Thermal protection properties of composite hydrogel's mainly behaved in three aspects: cooling, insulation and flame-retardant.

When heated, a lot of heat can be taken away by way of rapid evaporating of composite hydrogel. exhibiting a rapid cooling ability [1]. However, as to composite hydrogel, the modifier adjusts the interface state of hydrogel and air, weaken the attraction between water molecules on the surface and increasing potential energy, which makes hydrogel easier to vaporize when heated, and further accelerates the cooling rate [14] [15].

Moreover, all insoluble particles including heat-insulating particles, flame retardant particles and nanoparticles doped into hydrogels can give it further heat reflection, heat-insulating and flame-retardant properties, making three dimensional skeleton structure stable even at high temperatures at the same time. 


\subsection{Analysis of TPP Test}

Testing hydrogels' thermal protection performance is a brand-new problem, which has not been reported literarily. Thermal conductivity or thermal diffusivity is obviously inappropriate for evaluating instant thermal performance of hydrogels because of low accuracy and incomplete evaluating.

TPP test can evaluate thermal radiation and thermal conductivity of materials comprehensively with advantages of simplicity and intuition. Figure 2 shows the TPP test results of Sample 1 and Sample 2. It shows that Sample 2 with a thickness of $1 \mathrm{~mm}$ has an excellent thermal protection effect, which can protect a human body from secondary burning.

The morphology photos of hydrogels after TPP test is shown in Figure 3. It can be seen that Sample 1 is slightly carbonized, while Sample 2 only has a reduced thickness.

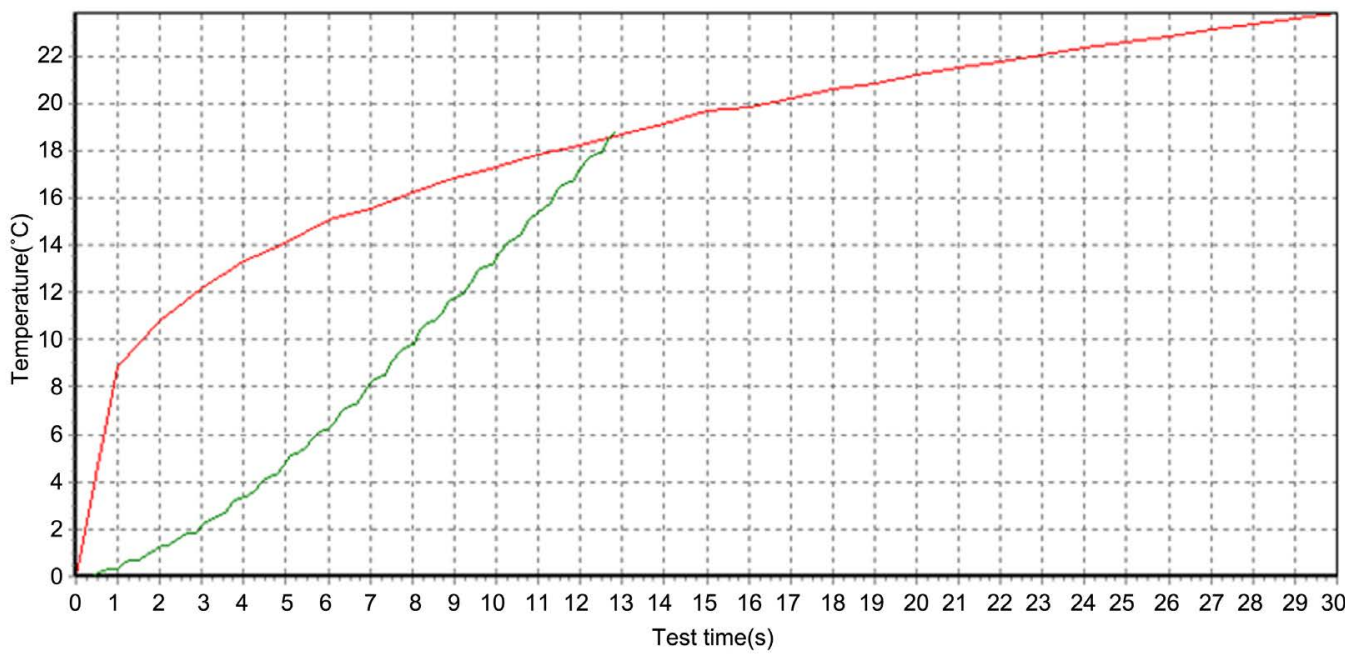

(a)

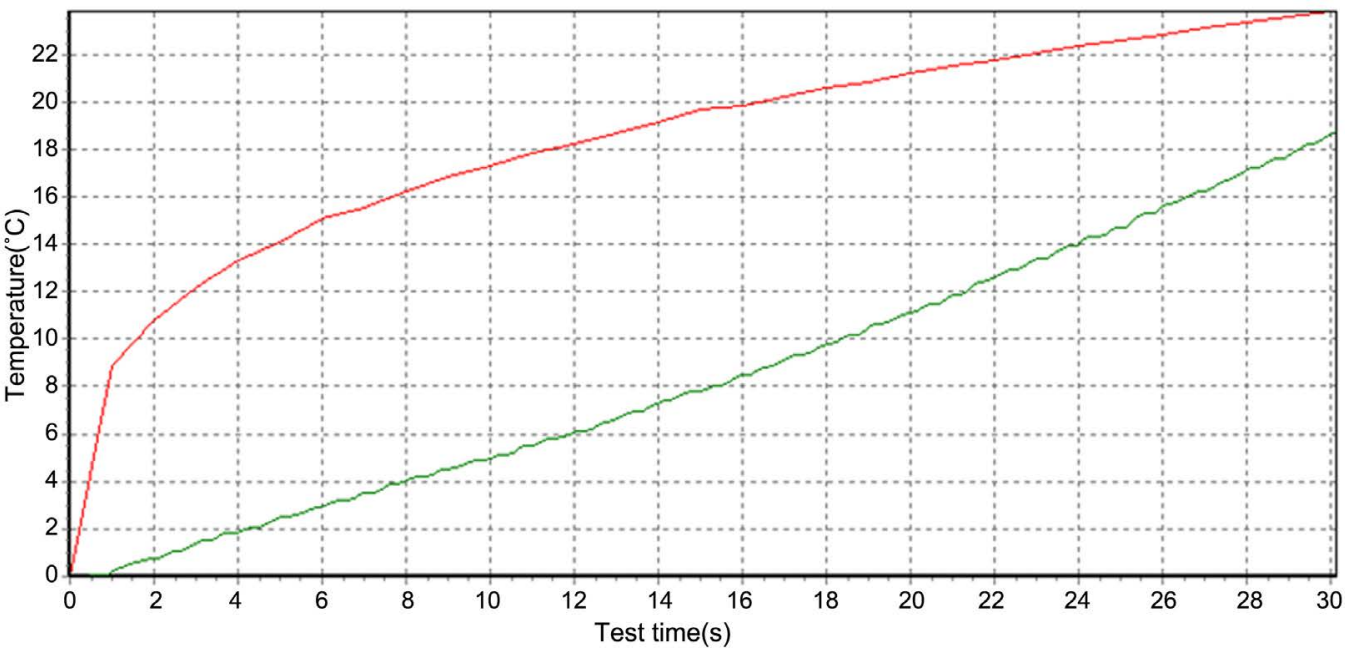

(b)

Figure 2. Screenshots of TPP test results of hydrogel with different coating thickness. Red line: Stoll standard curve; Green line: Heat flow response curve (a) Sample 1; (b) Sample 2. 


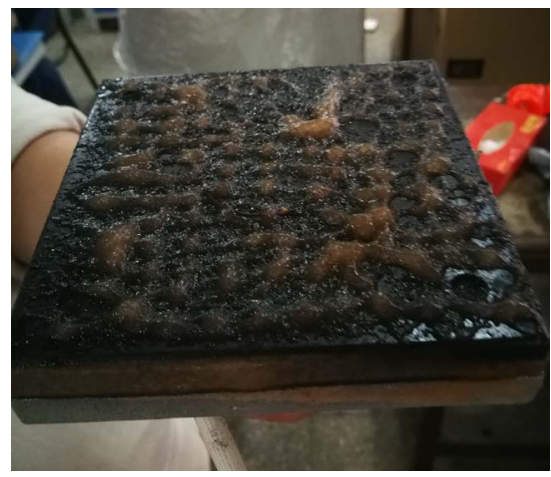

(a)

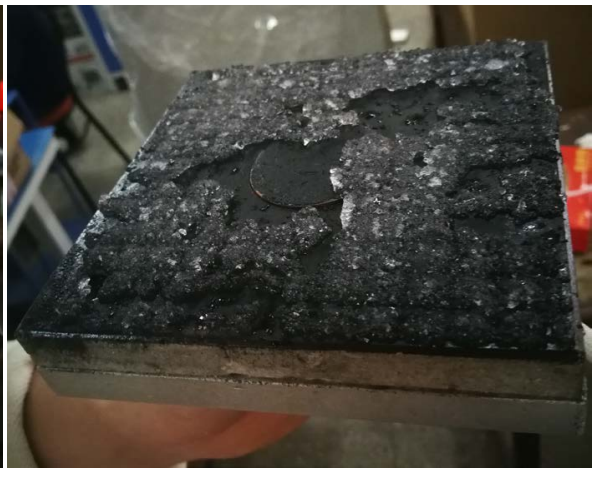

(b)

Figure 3. Morphology photos of hydrogels after TPP test (a) Sample 1; (b) Sample 2.

\subsection{Analysis of Adhesion Performance}

It is clear the thicker the hydrogel, the better the thermal protection performance. Hydrogel's thickness depends largely on its viscosity and strength. According to the adhesion test results of 2.3, hydrogel (1:200) adhesion thickness of Sample 1 - 5 was within the range of $5-8 \mathrm{~mm}$. As shown in Figure 4, hydrogel $(1: 125)$ can be easily turned upside down in a beaker, which indicates the success of composite dry powder's design on the other hand.

\subsection{Analysis of TG Test}

Hydrogel evaporates rapidly at $100^{\circ} \mathrm{C}$, absorbing a large amount of heat and losing most of weight, as shown in red and blue curve in Figure 5. During the process, the form stability of hydrogel is an important factor affecting its application. SAP has a thermal decomposition temperature of $400^{\circ} \mathrm{C}-500^{\circ} \mathrm{C}$, as shown in black curve. The insoluble particles help to maintain and stabilize hydrogel during thermal decomposition. So, appropriate insoluble components have a considerable contribution to thermal stability of hydrogels.

TPP test results show that composite hydrogels from Sample1-5 with only $1 \mathrm{~mm}$ thick ness have excellent thermal protection performances. Sample 2 and 3 even reach the upper limit of TPP.

\subsection{Analysis of Cooling Performance}

During TPP test, the temperature sensor's initial temperature must be down to room temperature $\left(20^{\circ} \mathrm{C} \pm 3^{\circ} \mathrm{C}\right)$. While after a TPP test, the sensor's final temperature rises to $63^{\circ} \mathrm{C} \pm 5^{\circ} \mathrm{C}$. So, during intensive TPP testing, every time after one sample test completed, the next sample test can only be carried out when the sensor has cooled down. It may take one hour or more to achieve this cooling process naturally. Usually the operator reduce time by means of repeated wet wipes, which only take 3 - 5 minutes.

However, during the TPP test period of this paper, composite hydrogel was tried for sensor's cooling. It only took $2-3$ seconds to cool the sensor from $58^{\circ} \mathrm{C}$ to $22^{\circ} \mathrm{C}$, which gives a strong proof that composite hydrogel has excellent cooling performance. 


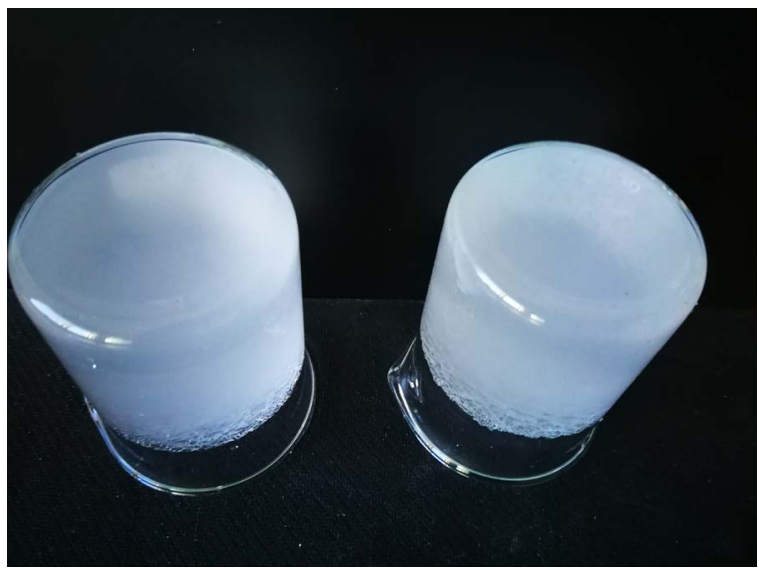

Figure 4. Hydrogel (1:125) can be easily turned upside down (Left: Sample 1 Right: Sample 2).

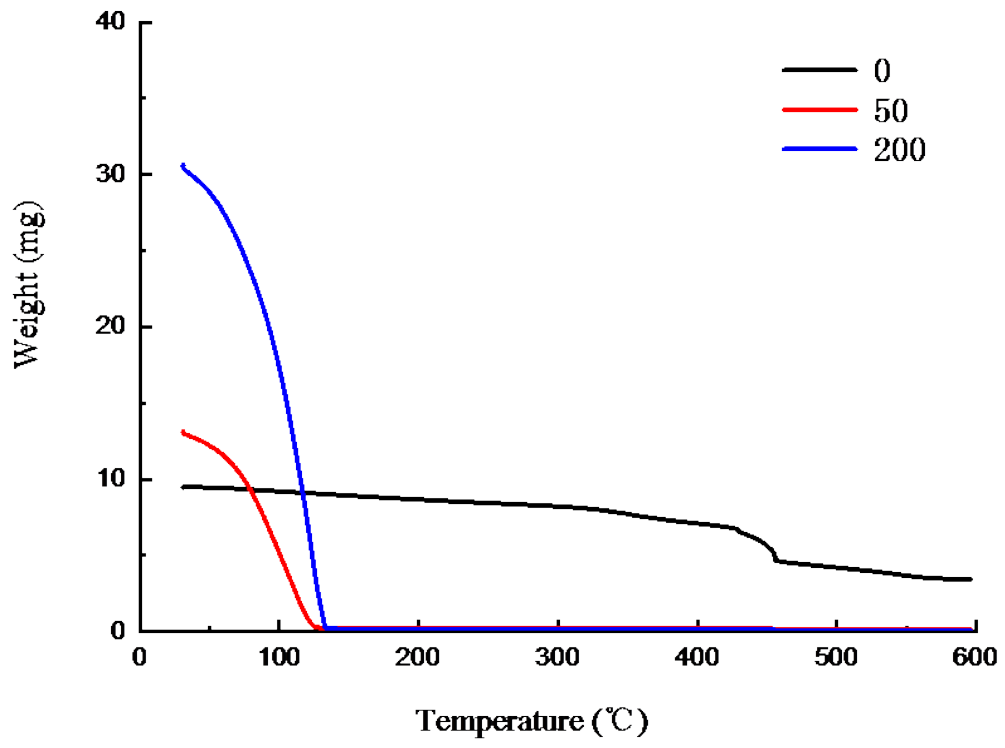

Figure 5. TG curves of polymer resins with different water absorption levels.

\section{Conclusions}

The composite cooling powder has the advantage of small in size and light in weight, which makes it easy for storage and long shelf life. It can be quickly and widely used when it is mixed with different water such as pure water, tap water, natural water, sea water, etc. The hydrogel formed is very easy to operate and use.

As a new thermal protection technology, this hydrogel material has excellent thermal protection performance, soft, green environmental protection, good skin adhesion and non-toxic or non-irritating features. It can be estimated optimistically that the new thermal protection material will be applied in a large scale.

\section{Conflicts of Interest}

The author declares no conflicts of interest regarding the publication of this paper. 


\section{References}

[1] Zhang, T., Xu, Z.G., Gui, H.G. and Guo, Q.P. (2017) Emulsion-Templated, Macroporous Hydrogels for Enhancing Water Efficiency in Fighting Fires. Journal of materials chemistry A, 5, 10161-10164. https://doi.org/10.1039/C7TA02319G

[2] Mechtcherine, V. and Reinhardt, H.W. (2012) Application of Super Absorbent Polymers (SAP) in Concrete Construction: State-of-the-Art Report Prepared by Technical Committee 225-SAP.Vol. 2, Springer, Dordrecht.

https://doi.org/10.1007/978-94-007-2733-5

[3] Liao, R.Z., Yang, P.L. and Ren, S.M. (2012) Review on Super Absorbent Polymer Application for Improving Fertilizer Efficiency and Controlling Agricultural Non-Point Source Pollutions. Transactions of the Chinese Society of Agricultural Engineering, 28, 1-10. http://dx.chinadoi.cn/10.3969/j.issn.1002-6819.2012.17.001

[4] Obana, H., Okihashi, M., Kakimoto, S. and Hori, S. (1997) Determination of Acephate and Methamidophos in Foods Using Super-Absorbent Polymer. Analytical Communications, 34, 253-256. https://doi.org/10.1039/A704952H

[5] Cutting, K.F. (2009) Managing Wound Exudate Using a Super-Absorbent Polymer Dressing: A 53-Patient Clinical Evaluation. Journal of Wound Care, 18, 200-205. https://doi.org/10.12968/jowc.2009.18.5.42174

[6] Laftah, W.A., Hashim, S. and Ibrahim, A.N. (2011) Polymer Hydrogels: A Review. Polymer-Plastics Technology and Engineering, 50, 1475-1486.

https://doi.org/10.1080/03602559.2011.593082

[7] Kabiri, K., Omidian, H., Zohuriaan-Mehr, M.J. and Doroudiani, S. (2011) Superabsorbent Hydrogel Composites and Nanocomposites: A Review. Polymer Composites, 323, 277-289.

[8] Xu, Z.F., Zhang, N.C. and Cai, Z.Y. (2015) Study on Fire Extinguishing Mechanism of Polymer Gel. Forestry Labour Safety, No. 2, 25-26.

[9] Nambu, H., Umada, A., Watanabe, Y., Igarashi, T. and Amiya, T. (1999) Process for Producing Improved Super Absorbent Polymer. US Patent No. 5883158A.

[10] Tang, H.Q. (2019) Study on Improvement and Application of Adhesion of Polymer Hydrogel Extinguishing Agents. China Safety Science Journal, No. 4, 64-69.

[11] Chambers, D.R., Fowler Jr., H.H., Fujiura, Y. and Masuda, F. (1992) Super-Absorbent Polymer Having Improved Absorbency Properties. US Patent No. 5145906A.

[12] Gao, G.R., Du, G.L., Sun, Y.N. and Fu, J. (2015) Progress in Tough and Responsive Hydrogels. Materials China, 34, 571-581.

[13] Mewis, J. and Wagner, N.J. (2009) Thixotropy. Advances in Colloid and Interface Science, 147-148, 214-227. https://doi.org/10.1016/j.cis.2008.09.005

[14] Tang, Y.B. and Wang, H. (2018) Development of a Novel Bentonite-Acrylamide Superabsorbent Hydrogel for Extinguishing Gangue Fire Hazard. Powder Technology, 323, 486-494. https://doi.org/10.1016/j.powtec.2017.09.051

[15] Illeperuma, W.R., Rothemund, P., Suo, Z. and Vlassak, J.J. (2016) Fire-Resistant Hydrogel-Fabric Laminates: A Simple Concept That May Save Lives. ACS Applied Materials \& Interfaces, 8, 2071-2077. https://doi.org/10.1021/acsami.5b10538 